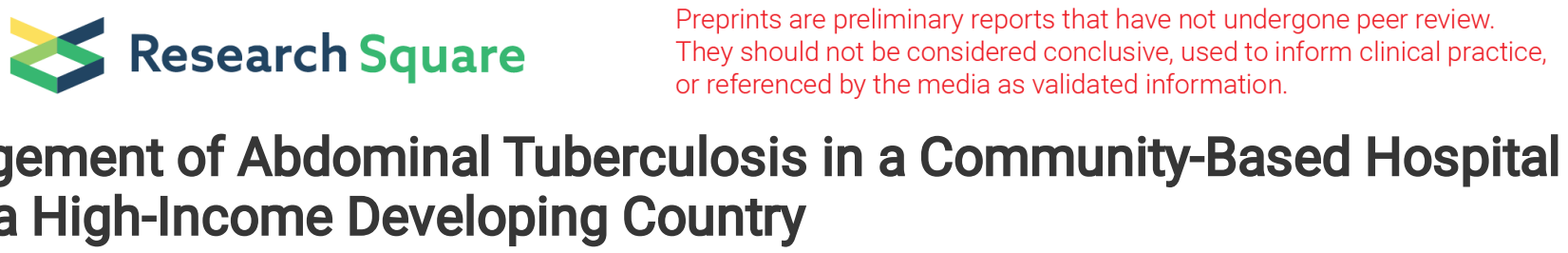

\title{
Management of Abdominal Tuberculosis in a Community-Based Hospital From a High-Income Developing Country
}

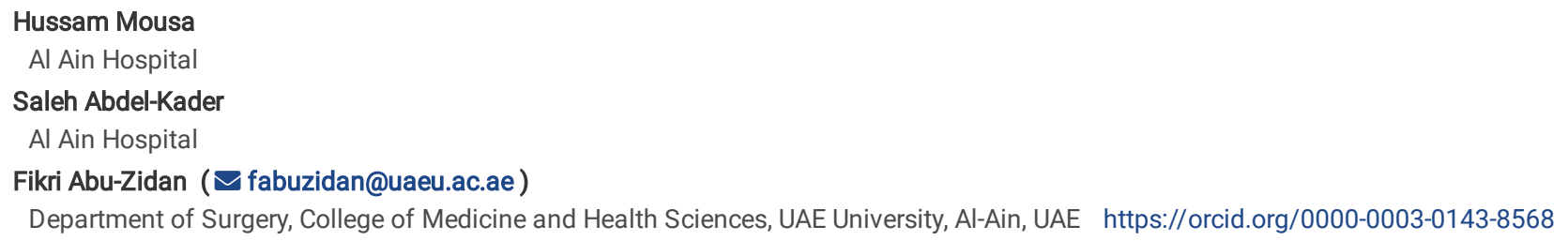

Hussam Mousa

Al Ain Hospital

Saleh Abdel-Kader

Al Ain Hospital

Fikri Abu-Zidan ( $\square$ fabuzidan@uaeu.ac.ae )

Department of Surgery, College of Medicine and Health Sciences, UAE University, Al-Ain, UAE https://orcid.org/0000-0003-0143-8568

\section{Research article}

Keywords: Tuberculosis, extrapulmonary, abdominal, diagnosis, surgery, management

Posted Date: February 18th, 2021

DOI: https://doi.org/10.21203/rs.3.rs-185819/v1

License: (c) (i) This work is licensed under a Creative Commons Attribution 4.0 International License. Read Full License 


\begin{abstract}
Background: The delayed diagnosis and management of abdominal tuberculosis increases its mortality. We aimed to study the clinical presentation, management, and outcome of patients who had abdominal tuberculosis and treated at Al-Ain Hospital, Al-Ain City, United Arab Emirates.
\end{abstract}

Methods: All patients who had abdominal tuberculosis and treated at Al-Ain Hospital between January 2011 and December 2018 were studied. Data were collected retrospectively using a structured protocol including demography, clinical presentation, diagnostic methods, management, and outcome.

Results: Twenty-four patients having a median age of 30 years were studied with an incidence of 0.6/100,000 population. The most common symptoms were abdominal pain (95.8\%) and malaise (79.2\%). Fever was present only in nine patients (37.5\%). Laboratory investigations, except the polymerase chain reaction immunoassay, were not helpful. Chest X-ray was abnormal in three patients (12.5\%). Ultrasound and abdominal CT scan were nonspecific. Thirteen patients needed surgical intervention for diagnosis or therapy. Diagnosis was confirmed by histopathology in 15 patients (62.5\%), immunological assays in 7 patients (29.2\%), microbiological culture in one patient (4\%), and therapeutic trial in one patient (4\%). The most common type of abdominal tuberculosis was gastrointestinal in 13 patients (54.2\%) followed by free wet peritonitis in five patients $(20.8 \%)$. All patients had quadruple anti-tuberculous therapy for a minimum of six months. The median hospital stay was 6.5 days. None of our patients died.

Conclusions: Diagnosis of abdominal tuberculosis remains challenging despite advancements in medical technology and diagnostic tools. The low percentage for the need for diagnostic therapy in our study supports the benefit of PCR assay. Surgery was mainly indicated as the last option to reach the diagnosis or to treat complications.

\title{
Introduction
}

Tuberculosis is one of the ten leading causes of death globally being responsible for the highest mortality caused by a single bacterium. Latent tuberculosis occurs in about one quarter of the world population. In 2019, ten million people had tuberculosis of whom 1.2 million died [1, 2]. Extrapulmonary tuberculosis accounts for $20 \%$ of tuberculosis [3]. Abdominal tuberculosis is the second most common site after pulmonary tuberculosis and accounts for $10-15 \%$ of all extra pulmonary cases $[4,5]$.

It is a misconception that abdominal tuberculosis is a disease of poor communities because it may occur in developed countries especially in immunocompromised patients [5]. This disease can be transmitted to the gastrointestinal tract by swallowing the infected sputum, to the lymph nodes and solid organs by lymphatic and hematogenous spread, and to the internal organs, like the fallopian tubes and adnexa in females, from adjacent infected foci [6-8]. Abdominal tuberculosis is a great mimicker for many diseases, such as malignancy and Crohn's disease, which may cause a major challenging diagnosis if not suspected [7-9]. Delayed diagnosis and treatment increase the mortality by about 10\% [10]. We aimed to study the clinical presentation, diagnosis, management, and outcome of patients who had abdominal tuberculosis and treated at Al-Ain Hospital, Al-Ain City, United Arab Emirates.

\section{Patients And Methods Ethical considerations}

Ethical approval has been given by Al -Ain Hospital Research Ethics Committee, Al-Ain, UAE, (Ethical approval number: AAHEC-04-20-009). Patients' informed consent was not required as the study was retrospective. Personal patients' identifiers were protected during data collection.

\section{Study Setting and Population}

Al-Ain Hospital was the main acute care surgery center in Al-Ain City having 550 beds till March 2021 when it was changed during the COVID-19 pandemic to be the COVID-19 care hospital of our city. The population of the Al-Ain City was estimated to be around half a miliion during the study period [11].

\section{Inclusion criteria}

All patients who had abdominal tuberculosis and treated at Al-Ain Hospital between January 2011 and December 2018 were included.

\section{Data collection}

Data were collected retrospectively. A special protocol was developed, tested, and refined before collecting the data. Data were collected by an experienced surgeon (S A-K) who was instructed and trained by the senior author (FAZ) to assure the accuracy of data collection. Collected data included demographics (age, gender, nationality), clinical presentation, diagnostic methods, type of abdominal tuberculosis, management, and clinical outcome.

\section{Statistical analysis}

Data were presented using summary descriptive statistics including median (range) for continuous or ordinal data and number (\%) for categorical data. Missing data were not imputed, and percentages were calculated from available data. The incidence was calculated by dividing the annual number of cases over the city population during the study period and expressed as cases per 100000 inhabitants. We used the Statistical Package for the Social Sciences (IBM-SPSS version 26, Chicago, II) for statistical analysis.

\section{Results}

Twenty-four patients having a median (range) age of 30 (19-59) years were studied. Thirteen (54.3\%) were females. All were expatriate workers, and none was a UAE national (Table 1). The incidence of abdominal tuberculosis was 0.6 per each 100,000 population. The most common presenting symptoms were 
abdominal pain (95.8\%), malaise (79.2\%) and loss of appetite (79.2\%). Fever was present only in nine patients (37.5\%) while night sweats were present only in six patients (25\%). The duration of symptoms ranged between two days to three years having a median duration of two months. The most common clinical findings were abdominal tenderness (75\%) and distension (37.5\%) (Table 2). Only two patients presented with a clear picture of peritonitis (8.3\%)

Table 1

Demography of 28 patients with abdominal tuberculosis who were treated at Al-Ain Hospital during the period of January 2011 to

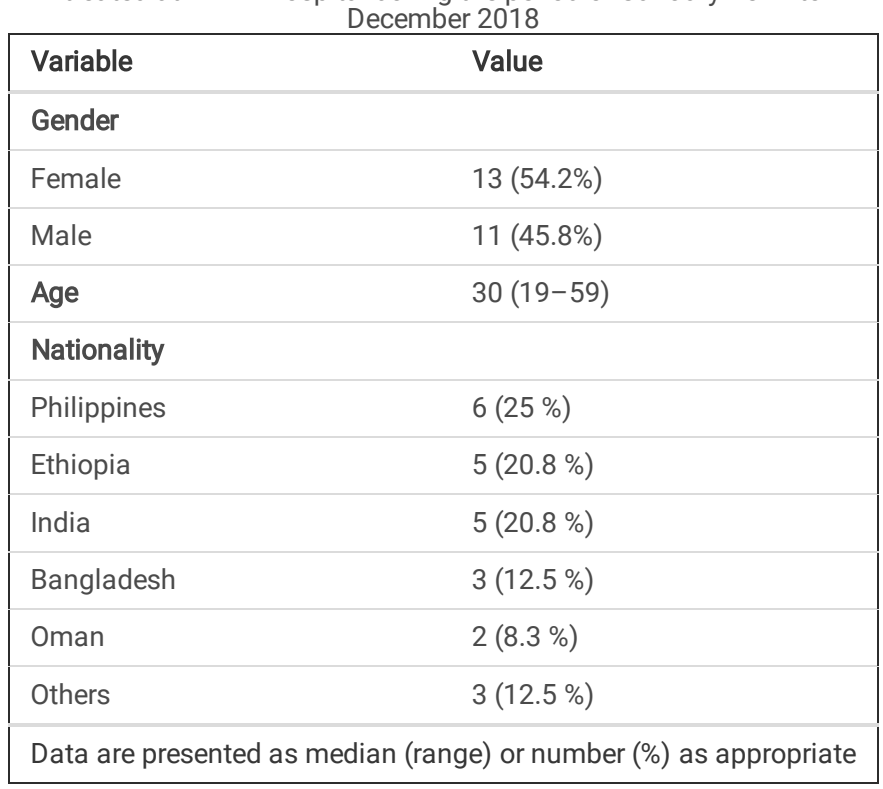

Table 2

Symptoms and signs of 28 patients with abdominal tuberculosis who were treated at Al-Ain Hospital during the period of January 2011 to December 2018

\begin{tabular}{|ll|}
\hline Variable & Number (\%) \\
\hline Symptoms & \\
\hline Abdominal pain & $23(95.8)$ \\
\hline Malaise & $19(79.2)$ \\
\hline Loss of appetite & $19(79.2)$ \\
\hline Nausea & $16(66.7)$ \\
\hline Loss of weight & $15(62.5)$ \\
\hline Diarrhea & $13(54.2)$ \\
\hline Fever & $9(37.5)$ \\
\hline Night sweats & $6(25)$ \\
\hline Vomiting & $5(20.8 \%)$ \\
\hline Signs & \\
\hline Tenderness & $18(75)$ \\
\hline Abdominal distension & $9(37.5)$ \\
\hline Guarding & $8(33.3)$ \\
\hline Ascites & $8(33.3)$ \\
\hline Rigidity & $2(8.3)$ \\
\hline Negative bowel sounds & $2(8.3)$ \\
\hline
\end{tabular}

Abdominal tuberculosis was suspected in 13 patients on admission (54.2\%). The second common suspected diagnosis was acute appendicitis (16.7\%) (Table 3). Two patients were discovered to have an associated abdominal tuberculosis during elective surgery when operated for another cause (gallstones and colonic adenocarcinoma). 
Table 3

Suspected diagnosis of 24 patients with proven abdominal tuberculosis who were treated at Al-Ain Hospital during the period of January 2011 to December 2018

\begin{tabular}{|ll|}
\hline Suspected diagnosis & Number (\%) \\
\hline Abdominal tuberculosis & $13(54.2)$ \\
\hline Acute appendicitis & $4(16.7)$ \\
\hline Abdominal mass & $3(12.5)$ \\
\hline Intestinal obstruction & $1(4.2)$ \\
\hline Peritonitis & $1(4.2)$ \\
\hline Biliary colic & $1(4.2)$ \\
\hline Abdominal wall abscess & $1(4.2)$ \\
\hline
\end{tabular}

C-reactive protein (CRP) was raised in 16 patients (80\%), leukocytosis was present in 3 patients (13.63\%), raised ESR in $4 / 8$ patients (57.14\%), anemia in 12 patients (50\%), lymphocytopenia in 3 patients (13.6\%), and thrombocytosis in $8 / 22$ patients (36.3\%) (Table 4)

Table 4

Blood investigations of 24 patients with abdominal tuberculosis who were treated at Al-Ain Hospital during the period of January 2011 to December 2018

\begin{tabular}{|l|l|}
\hline Blood investigations & Value \\
\hline CRP $($ normal value $<5 \mathrm{mg} / \mathrm{l})$ & $25.1(2-239)$ \\
\hline White bold cell count (normal value $\left.4.5-11 \times 10^{9} / \mathrm{l}\right)$ & $16 / 20(80 \%)$ \\
\hline$>11 \times 10^{9} / \mathrm{I}$ & $6.65(3.6-13.7)$ \\
\hline ESR $(0-20 /$ hour $)$ & $3 / 22(13.6 \%)$ \\
\hline$>20 /$ hour & $27(12-68)$ \\
\hline Hemoglobin (normal value $12.1-20 \mathrm{~g} / \mathrm{dl})$ & $4 / 8(50 \%)$ \\
\hline$<12 . \mathrm{g} / \mathrm{dl}$ & $11.7(7-16.5)$ \\
\hline Lymphocytes (normal value $1000-3.500 / \mu \mathrm{l})$ & $12(50 \%)$ \\
\hline$<1000 \mu \mathrm{L}$ & $1700(130-2800)$ \\
\hline Platelets (normal value $140-400 \times 1000 / \mathrm{ml})$ & $3 / 22(13.6 \%)$ \\
\hline$>400 \times 1000 / \mathrm{ml}$ & $338(156-711)$ \\
\hline Data are presented as median range or number $(\%)$ as appropriate. Percentages are calculated from available data. \\
\hline
\end{tabular}

Chest X-ray was abnormal in only three patients (12.5\%). Two had pleural effusion while the third had left apical pleural thickening and scaring suggesting pulmonary tuberculosis. Ultrasound was done in 13 patients. It showed abnormal findings in 11 patients. Sonographic findings included free intraperitoneal fluid in 4 patients, intraperitoneal soft tissue masses in three patients, intraperitoneal lymph nodes in three patients, thickened bowel in two patients, thickened omentum in two patients, encysted ascites in one patient (Fig. 1), abdominal wall mass in one patient and scarred kidneys in one patient.

Abdominal CT scan was done in 14 patients. Abdominal tuberculosis was suggested only in three patients, one had an omental cake and adenopathy, the second had a necrotic mass anterior and below the duodenum suggestive of a necrotic tuberculous adenopathy (Fig. 2), and the third had a thickened bowel with suspected pulmonary tuberculosis. The CT scan were generally nonspecific which included intra-abdominal lymphadenopathy in four patients, ileocecal mass in three patients, thickened bowel in three patients, free intraperitoneal fluid in two patients, pleural effusion in two patients, abdominal cocoon with dilated bowel in one patient, thickened omentum in one patient, hepatic calcification in one patient, and iliopsoas abscess connected with a sinus to an inflamed terminal ileum in one patient (Fig. 3).

Diagnosis was confirmed by histopathology showing caseating granuloma in 15 patients (62.5\%), two of these patients had acid fast bacilli on the slides. Immunological assays suggested the diagnosis in 7 patients (29.2\%). One patient grew mycobacterium tuberculosis (4\%). The workup of one patient was nonconclusive and had a therapeutic trial to confirm the diagnosis (4\%).

Table 5 shows the type of abdominal tuberculosis. The most common was gastrointestinal tuberculosis in 13 patients ( $54.2 \%)$ followed by the free wet peritonitis (ascites) in five patients (20.8\%). 
Table 5

Type of abdominal tuberculosis in 24

patients who were treated at Al-Ain

Hospital during the period of January 2011 to December 2018

\begin{tabular}{|ll|}
\hline Type & Number (\%) \\
\hline Gastrointestinal & $13(54.2)$ \\
\hline Wet peritonitis (ascites) & $5(20.8)$ \\
\hline Dry peritonitis & $4(18.2)$ \\
\hline Encysted ascites & $1(4.2)$ \\
\hline Lymphadenopathy & $1(4.2)$ \\
\hline
\end{tabular}

Thirteen patients had surgical operations. Five had laparoscopy, two were diagnostic for biopsies, three were therapeutic, all were converted to open surgery. Two of these patients had a right hemicolectomy while the third had cocoon encapsulating the small bowel, which was released. Six patients had laparotomy, two of them were in another hospital and then transferred to Al-Ain Hospital to continue their management. Two needed only a biopsy, two had small bowel resection anastomosis and two had right hemicolectomy. Two patients had abdominal wall surgery, an incision and drainage of an abscess and an excision of a mass. Three patients had postoperative complications (12.5\%); one patient had wound infection, another had pleural effusion, and a third had a sinus formation. All patients had quadruple anti-tuberculous therapy which included Isoniazid, Rifampin, Ethambutol, and Pyrazinamide for a minimum of six months. The patients stayed in the hospital for a median range of $6.5(0-21)$ days and were followed up for a period of (6-12) months. One of them needed readmission complaining of vomiting which resolved. None of our patients died.

\section{Discussion}

Our study has clearly shown that the clinical diagnosis of abdominal tuberculosis remains challenging despite advancements in medical technology and diagnostic tools. It was suspected in only half of our patients who were mainly adults in their thirties with equal male to female distribution similar to others [5, 12]. The incidence of abdominal tuberculosis was 0.6 per each 100000 population. Majority were low-income expatriate workers. Peritonitis, which is a late manifestation of the disease [7-10] occurred in less than $10 \%$ of our patients. The speedy development of a well-funded health care system in the United Arab Emirates (UAE), and the diversity of its population makes it an ideal setting for studying abdominal tuberculosis. The UAE has a 10 million population including more than 200 nationalities [13] as shown in Table 1.

Fever was present in less than $40 \%$ while leukocytosis was present in less than $15 \%$. If intra-abdominal pus was found by aspiration or surgery is a healthylooking patient who does not have fever and leukocytosis, abdominal tuberculosis should be suspected.

The laboratory and radiological workup were not very useful. Anemia and inflammatory markers, although alarming, are not specific [10]. Nevertheless, polymerase chain reaction (PCR) immunoassay tests suggested the diagnosis in seven patients (29.2\%). Chest-X-ray was normal in most of our patients. Only $15-25 \%$ of abdominal tuberculosis patients have associated pulmonary tuberculosis [14]. Similarly, sonographic findings are nonspecific although it may show ascites, lymphadenopathy, and focal organ lesions [15]. Abdominal CT Scan is more accurate than ultrasound and may indicate the need for further diagnostic measures such as percutaneous aspiration or direct biopsy $[15,16]$. It is useful in defining the type and evaluating the extent of abdominal tuberculosis $[14,17,18]$. CT scan findings include ascites, peritoneal thickening, lymph nodes enlargement, bowel wall thickening, and mesenteric fat stranding. These are difficult to differentiate from lymphomas, peritoneal carcinomatosis, and inflammatory bowel diseases [19, 20].

Fine needle aspiration cytology may demonstrate granulomatous cells necessitating the start of early medical therapy which will avoid laparoscopy or laparotomy [12]. In our study, the diagnosis was established histologically in 15 cases (62.5\%). The decision for using laparoscopy or laparotomy as a diagnostic method depends on the laparoscopic experience of the surgeon and the type of abdominal tuberculosis. Diagnostic laparoscopy is useful in obtaining tissue samples [21] especially in ascitic peritonitis. Open surgery is indicated in cases of tuberculous abdominal cocoon to peel off the fibrous tissue encasing the bowel to avoid bowel injury as occurred in one of our patients [22].

Therapeutic diagnosis has a role in the presence of high index of suspicion of abdominal tuberculosis and a negative workup [9]. This is especially important when abdominal tuberculosis cannot be differentiated from Crohn's disease [6]. Treating abdominal tuberculosis with steroids on the assumption that it is Crohn's disease is very risky and may lead to death $[4,10]$. Therapeutic diagnosis was used in around $25 \%(16-29 \%)$ of abdominal tuberculosis in old studies [23-26]. We used this approach only in one patient (4\%) which indicates improvements in the diagnostic accuracy. The new immunoassay tests suggested the diagnosis in 7 patients (29.2\%). It is possible that $8 / 24$ (33\%) would have needed a therapeutic trial if the PCR immunoassay tests were not available. PCR assay may support the clinical diagnosis. Nevertheless, it cannot differentiate between dead and living mycobacterium because it stays to be positive for a long time after the death of the bacteria. Accordingly, PCR should not be used for follow-up [27, 28].

In principle, abdominal tuberculosis should be treated medically, and surgery should be performed only when indicated, which is usually as the last option to reach a diagnosis or to treat complications. Globally, $20-40 \%$ of abdominal tuberculosis present acutely and need emergency surgery. Indications for surgery include bowel obstruction, perforation and bleeding $[5,7,10]$. In our study 13 out of 24 patients $(54.2 \%)$ needed surgery. The median duration of hospital stay in our study was 6.5 days which is less than that reported by other authors [5]. None of our patients died because they were young without underlying comorbidities. The UAE has generally a young working population with very low mortality of severe sepsis of less than $1 \%$ [29]. 


\section{Limitations}

We must acknowledge that our study has certain limitations. First, the sample size is relatively small. Nevertheless, it represents all patients treated over eight years in a major hospital with a catchment population of half million inhabitants. Second, the study is retrospective in nature which carries the risk of missing data. Finally, we could not locate the source of infection which is important for infection control. The majority were expatriate workers suggesting that the infection was carried from overseas although we cannot be sure about that.

\section{Conclusions}

Diagnosis of abdominal tuberculosis remains challenging despite advancements in medical technology and diagnostic tools. The low percentage for the need for diagnostic therapy in our study supports the benefit of PCR assay. Surgery was mainly indicated as the last option to reach the diagnosis or to treat complications.

\section{Abbreviations}

CT

computed tomography

ESR

erythrocyte sedimentation rate

PCR

polymerase chain reaction

UAE

United Arab Emirates

\section{Declarations}

Ethics considerations: Ethical approval has been given by Al -Ain Hospital Research Ethics Committee, Al-Ain, UAE, (Ethical approval number: AAHEC-04-20009). Patients' informed consent was not required as the study was retrospective. Personal patients' identifiers were protected during data collection.

Consent for publication: Not applicable

Availability of data and material: Data will be available to The Editor on request

Competing interests: The authors declare that they have no competing interests.

Funding: None.

Contribution of authors: Conceived and designed the experiments: HM, FAZ, Retrieved and coded the data: HM, S A-K, Analyzed the data: FAZ. Wrote the paper: HM, FAZ. Critically read the paper: HM, S A-K, FAZ. Approved final version: HM, S A-K, FAZ.

Acknowledgements: Not applicable

Authors' information (optional): Not applicable

\section{References}

1. World Health Organization. Global tuberculosis report 2020, World Health Organization, Geneva. 2020, https://www.who.int/publications/i/item/9789240013131 (accessed January 25, 2021).

2. Houben RM, Dodd PJ. The global burden of latent tuberculosis infection: a re-estimation using mathematical modelling. PLoS Med. 2016;13:e1002152-2.

3. Yang Z, Kong Y, Wilson F, Foxman B, Fowler AH, Marrs CF, Cave MD, Bates JH. Identification of risk factors for extrapulmonary tuberculosis. Clin Infect Dis. 2004;38:199-205.

4. Rathi P, Gambhire P. Abdominal Tuberculosis. J Assoc Physicians India. 2016;64:38-47.

5. Chalya PL, Mchembe MD, Mshana SE, Rambau PF, Jaka H, Mabula JB. Clinicopathological profile and surgical treatment of abdominal tuberculosis: a single centre experience in northwestern Tanzania. BMC Infect Dis. 2013;13:270.

6. Abu-Zidan FM, Sheek-Hussein M. Diagnosis of abdominal tuberculosis: lessons learned over 30 years: pectoral assay. World J Emerg Surg. $2019 ; 14: 33$.

7. Pattanayak S, Behuria S. Is abdominal tuberculosis a surgical problem? Ann R Coll Surg Engl. 2015;97:414-9.

8. Alhajri K, Alzerwi N, Alsaleh K, Yousef HB, Alzaben M. Disseminated (miliary) abdominal tuberculosis after laparoscopic gastric bypass surgery. BMJ Case Rep. 2011;2011:bcr1220103591. doi:10.1136/bcr.12.2010.3591.5.

9. Khan R, Abid S, Jafri W, Abbas Z, Hameed K, Ahmad Z. Diagnostic dilemma of abdominal tuberculosis in non-HIV patients: an ongoing challenge for physicians. World J Gastroenterol. 2006;12:6371-5.

10. Weledji EP, Pokam BT. Abdominal tuberculosis: Is there a role for surgery? World J Gastrointest Surg. 2017;9:174-81. doi:10.4240/wjgs.v9.i8.174. 
11. Macrotrends. Al-Ain UAE, Metro Area. Population 1950-2021. Available on: https://www.macrotrends.net/cities/22634/al-ain/population (Accessed 25 January 2021).

12. Rana S, Farooqui MR, Rana S, Anees A, Ahmad Z, Jairajpuri ZS. The role of laboratory investigations in evaluating abdominal tuberculosis. J Family Community Med. 2015;22:152-7.

13. The United Arab Emirates' Government portal. Fact sheet. https://u.ae/en/about-the-uae/factsheet\#: :text=The\%20UAE\%20is\%20a\%20constitutional,the\%20capital\%20of\%20the\%20UAE.\&text=Recognised\%20as\%20a\%20tolerant $\% 20$ country,learni (Accessed 26 January 2021).

14. Debi U, Ravisankar V, Prasad KK, Sinha SK, Sharma AK. Abdominal tuberculosis of the gastrointestinal tract: revisited. World J Gastroenterol. 2014;20:14831-40.

15. Sheikh M, Abu-Zidan F, al-Hilaly M, Behbehani A. Abdominal tuberculosis: comparison of sonography and computed tomography. J Clin Ultrasound. 1995;23:413-7.

16. Akhan O, Pringot J. Imaging of abdominal tuberculosis. Eur Radiol. 2002;12:312-23.

17. Abu-Zidan F, Al-Hilaly M, Mohtasib S, Denath F, Diab S. Role of CT Scan in the diagnosis of abdominal tuberculosis. In: Montorsi M, Zennaro F, editors. Proceedings of the Second World Week of Professional Updating in Surgery and Oncological Disciplines of the University of Milan. General Surgery, Vol VII. Monduzzi Editore, Bologna, Italy, 1990: 35-40.

18. Suri S, Gupta S, Suri R. Computed tomography in abdominal tuberculosis. Br J Radiol. 1999;72:92-8.

19. Tirumani SH, Ojili V, Gunabushanam G, Shanbhogue AK, Nagar A, Fasih N, Chintapalli KN. Imaging of tuberculosis of the abdominal viscera: beyond the intestines. J Clin Imaging Sci. 2013;3:17. doi:10.4103/2156-7514.111234.

20. da Rocha EL, Pedrassa BC, Bormann RL, Kierszenbaum ML, Torres LR, D'Ippolito G. Abdominal tuberculosis: a radiological review with emphasis on computed tomography and magnetic resonance imaging findings. Radiol Bras. 2015;48:181-91. doi:10.1590/0100-3984.2013.1801.

21. Rai S, Thomas WM. Diagnosis of abdominal tuberculosis: the importance of laparoscopy. J R Soc Med. 2003;96:586-8.

22. Wani I, Ommid M, Waheed A, Asif M. Tuberculous abdominal cocoon: original article. Ulus Travma Acil Cerrahi Derg. 2010;16:508-10.

23. Abu-Zidan F, Al-Hilaly M, Diab S. Abdominal tuberculosis in Kuwait. In: Montorsi M, Zennaro F, editors. Proceedings of the Second World Week of Professional Updating in Surgery and Oncological Disciplines of the University of Milan. General Surgery, Vol VII. Monduzzi Editore, Bologna, Italy, 1990: 41-46.

24. Shah S, Thomas V, Mathan M, Chacko A, Chandy G, Ramakrishna BS, Rolston DD. Colonoscopic study of 50 patients with colonic tuberculosis. Gut. 1992;33:347-51.

25. Singh V, Kumar P, Kamal J, Prakash V, Vaiphei K, Singh K. Clinicocolonoscopic profile of colonic tuberculosis. Am J Gastroenterol. 1996;91:565-8.

26. Uygur-Bayramicli O, Dabak G, Dabak R. A clinical dilemma: abdominal tuberculosis. World J Gastroenterol. 2003;9:1098-101.

27. American Thoracic Society. Diagnostic standards and classification of tuberculosis in adults and children. Am J Respir Crit Care Med. 2000;161:1376-95.

28. Mehta PK, Raj A, Singh N, Khuller GK. Diagnosis of extrapulmonary tuberculosis by PCR. FEMS Immunol Med Microbiol. 2012;66:20-36.

29. Abdel-Kader S, Sartelli M, Abu-Zidan FM. Complicated intra-abdominal infections: a prospective validation study of the WSES Sepsis Severity Score. Singapore Med J. 2019;60:317-21.

\section{Figures}



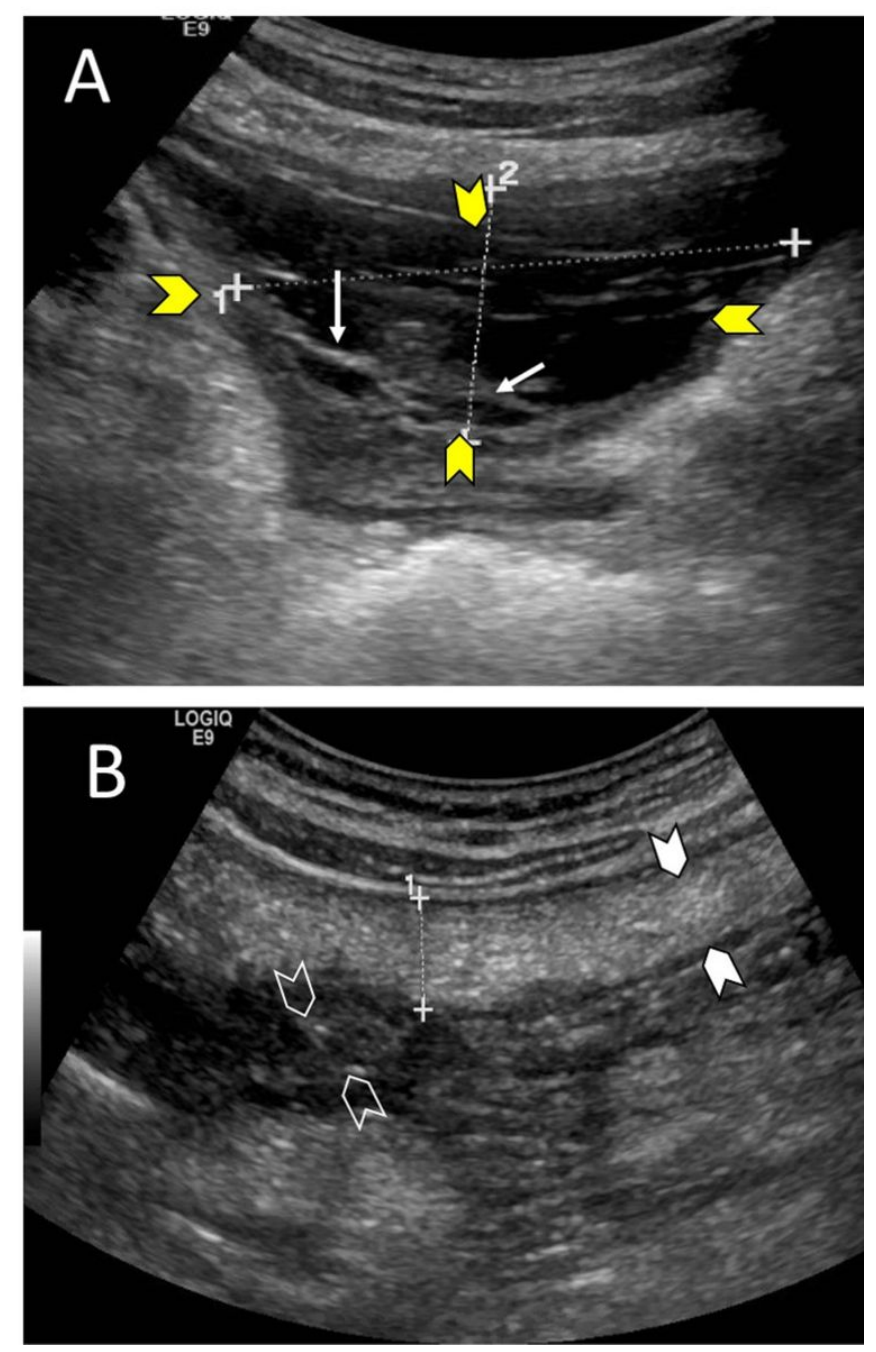

\section{Figure 1}

A 29-year-old man presented with shortness of breath, generalized abdominal pain, and fatigue. Abdominal ultrasound scan showed ascites (A, yellow arrow heads) with loculations ( $A$, white arrows) in the pelvis and the left iliac fossa. The peritoneum ( $B$, white arrow heads) and omentum (B, empty arrow heads) were thickened. Peritoneal and pleural fluid cytology were suggestive of an inflammatory tuberculous process. The patient responded to the anti-tuberculous therapy. 


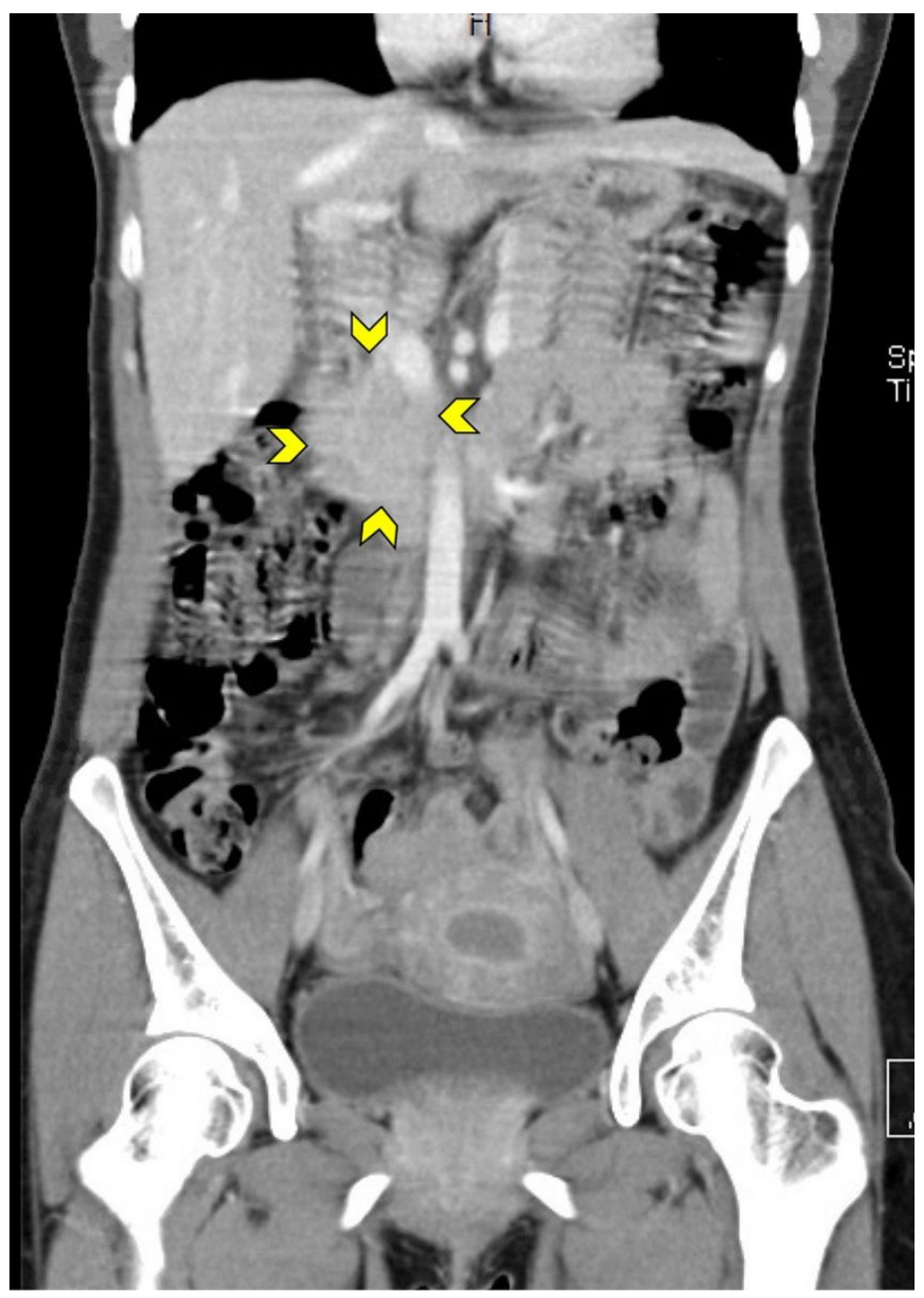

Figure 2

A 29-year-old woman presented with epigastric and lower abdominal pain, fresh vaginal bleeding and weight loss. Coronal CT scan of the abdomen with intravenous contrast revealed a non-enhanced complex mass lesion measures $4 \times 2.5 \mathrm{~cm}$ anterior and to the right of the IVC at the level of L3-L4 vertebrae suggesting matted lymph nodes (arrows). Acid Fast Bacilli smear from the mass was positive. 


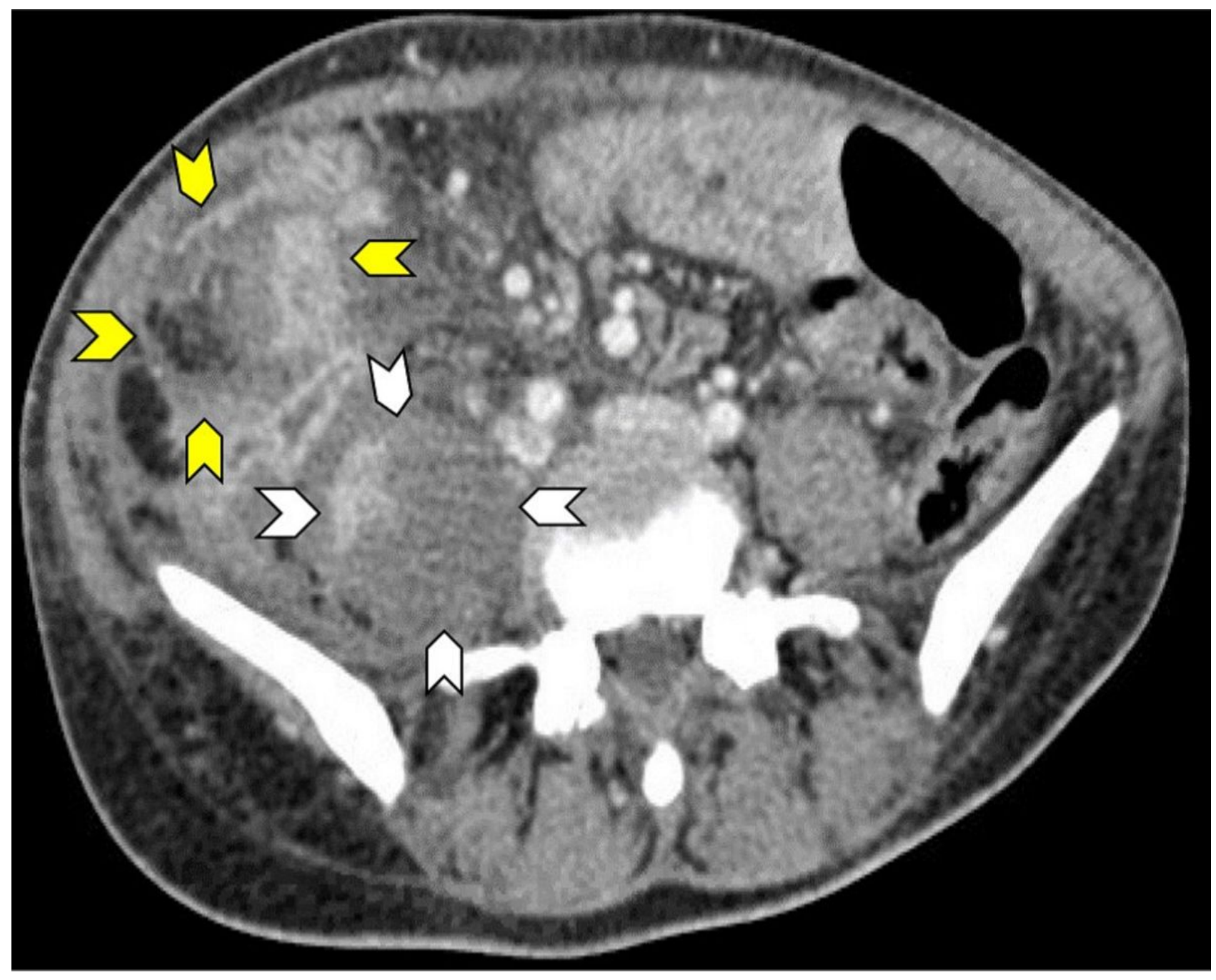

Figure 3

A 31-year-old woman presented with right iliac fossa and right sided back pain for one-month duration. She was afebrile, had no cough or night sweats but was anemic. Abdominal CT scan with intravenous contrast showed an inflammatory mass in the right iliac fossa (yellow arrow heads) with sinus tracts communicating to a right iliopsoas abscess (white arrow heads). The patient was from an endemic area of tuberculosis and was treated with anti-tuberculous drugs. 